\title{
Long-term statistical assessment of meteorological indicators and COVID-19 outbreak in hot and arid climate, Bahrain
}

\author{
Adeb Qaid ${ }^{1}$ (D) $\cdot$ Muhammad Farhan Bashir ${ }^{2}$ (D) Dilshan Remaz Ossen ${ }^{1} \cdot$ Khurram Shahzad $^{3}$ (D) \\ Received: 18 March 2021 / Accepted: 8 July 2021 / Published online: 4 August 2021 \\ (C) The Author(s), under exclusive licence to Springer-Verlag GmbH Germany, part of Springer Nature 2021, corrected publication 2021
}

\begin{abstract}
The COVID-19 pandemic has significantly impacted the global lifestyle, and the spreading of the virus is unprecedented. This study is aimed at assessing the association between the meteorological indicators such as air temperature $\left({ }^{\circ} \mathrm{C}\right)$, relative humidity $(\%)$, wind speed (w/s), solar radiation, and $\mathrm{PM}_{2.5}$ with the COVID-19 infected cases in the hot, arid climate of Bahrain. Kendall and Spearman rank correlation coefficients and quantile on quantile regression were used as main econometric analysis to determine the degree of the relationship between related variables. The dataset analysis was performed from 05 April 2020 , to 10 January 2021. The empirical findings indicate that the air temperature, humidity, solar radiation, wind speed indicators, and PM2.5 have a significant association with the COVID-19 newly infected cases. The current study findings allow us to suggest that Bahrain's relatively successful response to neighboring GULF economies can be attributed to the successful environmental reforms and significant upgrades to the health care facilities. We further report that a long-term empirical analysis between meteorological factors and respiratory illness threats will provide useful policy measures against future outbreaks.
\end{abstract}

Keyword COVID-19 $\cdot$ Newly confirmed cases $\cdot$ Meteorological indicators $\cdot$ Hot $\cdot$ Arid climate $\cdot$ Bahrain $\cdot$ Statistical correlation

On 31 December 2019, the World Health Organization (WHO) was informed about a novel infectious disease in Wuhan City, Hubei, China (Fofana et al. 2020). On 12 January 2020, The

The original online version of this article was revised: Table 2 is missing in the original paper.

Responsible Editor: Philippe Garrigues

Khurram Shahzad

khurrams.khurram@gmail.com

Adeb Qaid

a.alameri@ku.edu.bh; adeebqaid@gmail.com

Muhammad Farhan Bashir

farhan.paks89@gmail.com; farhan.paks@csu.edu.cn

Dilshan Remaz Ossen

d.ossen@ku.edu.bh; ardrossen@gmail.com

1 Department of Architecture Engineering and Design, Kingdom University, Riffa, Kingdom of Bahrain

2 Business School, Central South University, Changsha 410083, Hunan, People's Republic of China

3 Key Laboratory of Resource Biology and Biotechnology in Western China, Ministry of Education, College of Life Sciences, Northwest University, Xi'an, People's Republic of China
WHO confirmed that a novel coronavirus was the cause of these diseases. This virus is the seventh member of coronaviruses that infect humans (Zhu et al. 2020). On 11 March 2020, the WHO announced that the novel coronaviruses is a COVID-19 outbreak, a global pandemic (Arslan et al. 2021; Cucinotta and Vanelli 2020). Recent months have seen the COVID-19 pandemic (Li et al. 2020; Yao et al. 2020) affects many people and industries in countries around the world (Li et al. 2020; Bashir et al. 2020b, 2020c), including the countries of the Gulf Cooperation Council (GCC) in the Middle East. The first COVID-19 cases appeared at the end of February 2020 in most of the gulf countries. In March 2020, several strict policies were adopted by the governments of the Gulf Cooperation Council to control the virus, including partial and full curfews in the daytime and nighttime, depending on the assessment of the Ministries of Health on the spread of the outbreak. During the year, partial and total lockdowns were applied from time to time, with the re-openings depending on the number of confirmed cases and deaths. Preventive measures included banning land and air transportation between GCC countries and abroad countries that have been infected with coronaviruses. In addition, all GCC governments temporarily suspended or closed all business and commercial activities, industrial activities, religious worship, public and private schools, colleges, universities, movie theaters, 
gyms, public swimming pools, theme parks, and malls with restaurants and coffee shops. However, these activities gradually resumed during June and July 2020.

According to Paraskevis et al. (2021), over 103 million people are infected with the virus, and around 2,23 million people have died due to it, and the number is increasing each day. Other regions, however, have implemented other measures to contain the infectious disease outbreak until the line of infected cases is flattened by the end of October 2020. The outbreak experienced a second wave in the early months of November 2020, peaked in June 2021. There have been many more cases reported in the second wave of the outbreak than in the first wave in different countries worldwide, including in the GCC region (Bashir et al. 2020d; Diaz and Vergara 2020; HOPKINS 2021; Tayech et al. 2020). In the second wave of COVID19, Bahrain reported the highest number of confirmed and death cases among GCC countries (see Fig. 1). Many governments continued similar measures implemented in the first wave to control the virus spread (Bilal et al. 2021a, b). According to WHO, the COVID-19 is transmitted mainly by people interaction; the longer the interaction, the higher the transmission rate. However, the virus can also be transmitted airborne by larger droplets and aerosols. Larger droplets turn into aerosols, known as droplet nuclei, through evaporation (Bilal et al. 2021c). However, the relative importance of larger droplets and aerosols is still a subject of debate as of November 2020. More studies will be necessary to clarify this.

Another study in the moderate climate of different cities in Turkey Şahin (2020) highlighted that the highest correlations were observed for population, wind speed for 14 days, and temperature in the daytime. Biktasheva (2020) claimed that habitat's air humidity negatively correlated with COVID-19 morbidity and mortality in Germany. In the past, humidity was perceived as a factor in transmitting influenza. A recent analysis study conducted by Bilal et al. (2021a) in the most affected states of the USA concluded that climatic factors of temperature, humidity, environmental quality index, $\mathrm{PM}_{2.5}$, and rainfall are significant factors related to the COVID-19 pandemic. According to Luo et al. (2020), cold and dry environments facilitated spreading droplet-mediated viral disorders, and warm and humid environments attenuated viral transmission.

In contrast, different regions of the earth have different climate conditions that might impact their ecosystems differently and transmission of diseases. A critical review study by Shakil et al. (2020) reported that most of the COVID-19 studies had been conducted in countries with low temperatures. Thus, future studies should consider countries with high
Fig. 1 Daily confirmed new and death cases (ourworldindata 2021)

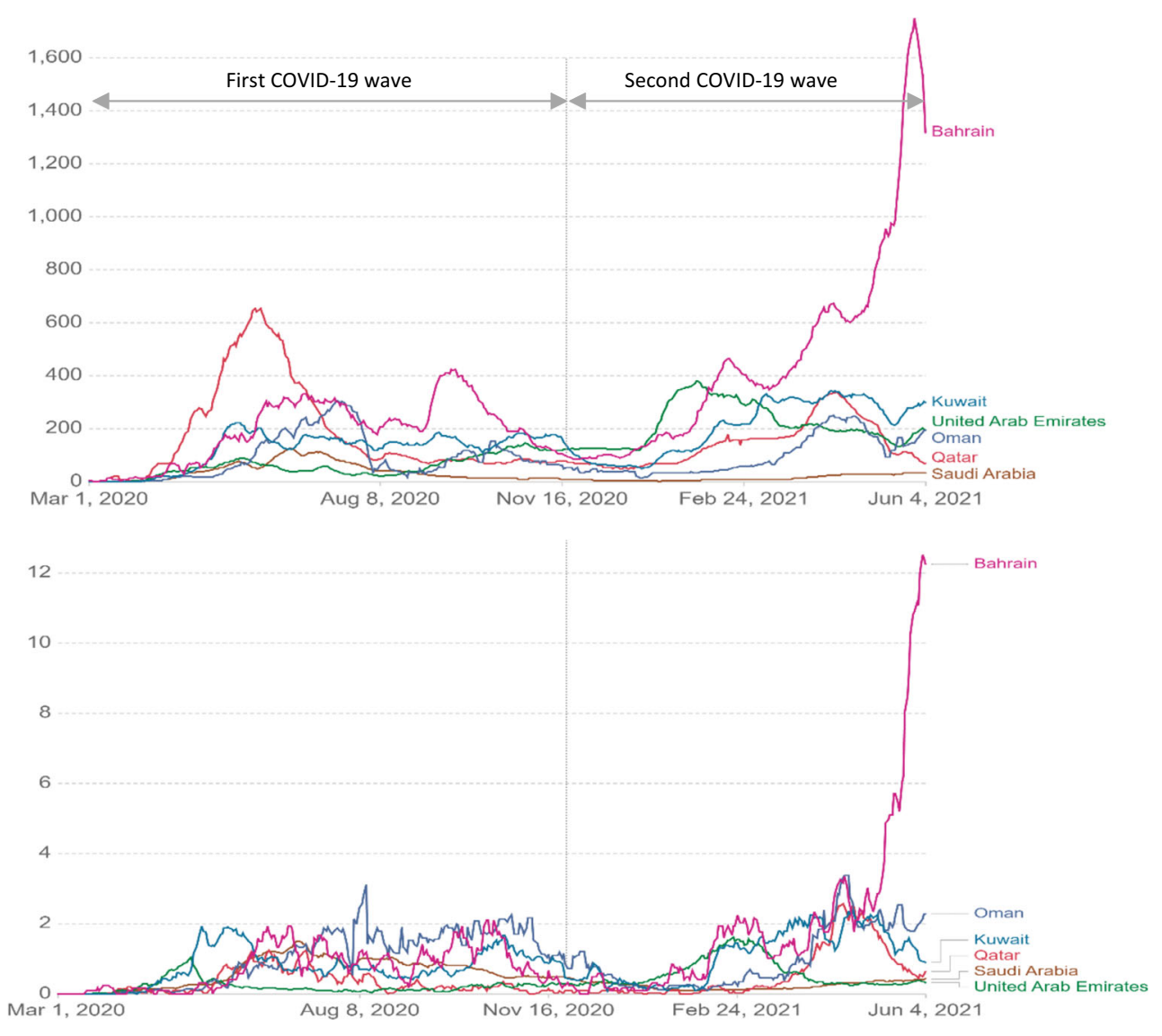


temperatures and humidity. Paraskevis et al. (2021) state that weather variables impact COVID-19 outbreaks, but containment measures and public health interventions of the country must be considered alongside.

The purpose of this study is to examine the effect of meteorological factors on spreading COVID-19 under Bahrain's extremely hot and arid climate for controlling COVID-19 outbreak in the future. Despite a large number of cases, deaths from the pandemic in Bahrain remain low, as shown in Fig. 2. It is mainly because the country applied the necessary containment measures, and the ministry of health consistently outlined the conditions to restrain the virus outbreak (Health 2021). Thus, we suggest assessing the severity of climate influences on the disease's spread is crucial to determining the effectiveness of mitigation strategies.

\section{Middle East and Bahrain case study}

Middle Eastern countries, such as Bahrain, Kuwait, Oman, Qatar, Saudi Arabia, and the United Arab Emirates, have desert terrain and arid climates. In recent months, this region has experienced the second wave of the COVID-19 pandemic. The climate impact of the COVID-19 outbreak on this region is not adequately studied. A similar disease known as the novel coronavirus (MERS-CoV) was reported in this area. Altamimi and Ahmed (2020) cited climate as a factor contributing to the spread of the disease. Bahrain has been selected to assess the meteorological factors that impact COVID-19 cases since it is a small desert island. Because of an Island, meteorological factors such as air temperature, air humidity, wind speed, and solar radiation affect all areas equally throughout the year. In a big country, due to the diversity of land types and the density of built-up areas, the climate can vary significantly.

Moreover, Bahrain's population density is concentrated in the North of the island, and it is not dispersed across the whole country, as it is in other countries. In addition, there is no

COVID-19 total deaths

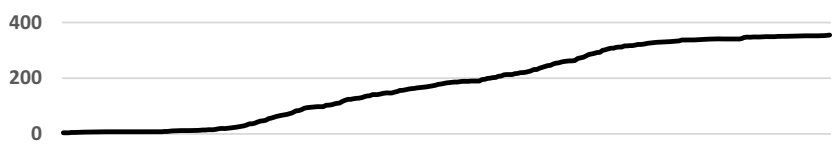

COVID-19 total cases

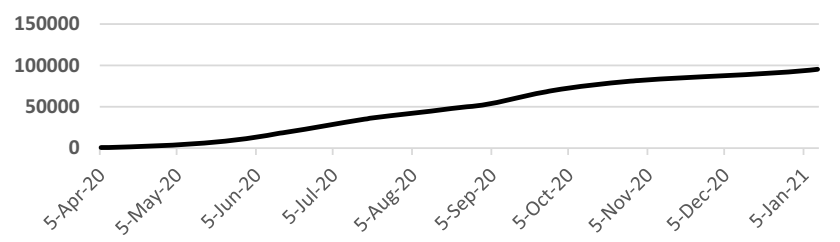

Fig. 2 COVID-19 pandemic in Bahrain population migration from one city to another, contributing to the spread of the pandemic. Despite implementing restricted measures, due to its size and population, the number of new cases and deaths related to COVID-19 remained higher in Bahrain than in other GCC countries. For these reasons, Bahrain was selected for an in-depth study of the association between climate factors in hot arid region with the COVID-19 pandemic to find solutions to reduce the spread of the infected cases.

Bahrain featured a hot and arid climate with two main seasons, with extreme summer from June to September and a relatively mild winter season from December to March. The two transitional periods' main two seasonal variations were separated from April/May and October/November. From April to October, daytime air temperature gradually increases, and relative humidity dramatically decreases, and the average afternoon air temperatures are $40^{\circ} \mathrm{C}$. Sometimes, it can reach up to $48^{\circ} \mathrm{C}$ between June and July. The minimum relative humidity is about $47 \%$ and the maximum relative humidity between $75 \%$ and $80 \%$. However, the intensity of the heat and the humidity make these months thermally discomfort conditions. In the winter months, from December to March, the temperature ranges between $10^{\circ} \mathrm{C}$ and $20^{\circ} \mathrm{C}$, while the humidity rises above $90 \%$. Therefore, the influence of these extreme air temperature and relative humidity variations are investigated in this study. During winter, the sky is partly cloudy, while in the summer, the sky is clear. The highest average solar radiation is $800 \mathrm{w} / \mathrm{m}^{2}$, which occurs in June. The mean annual precipitation is very low and limited $(70.8 \mathrm{~mm})$, and irregular mostly falls between November and April.

During the summer, a Southwest hot-dry wind periodically blows sand clouds across the barren southern part of Bahrain toward Manama. During the winter months, the prevailing winds from the Southeast bring damped air over the islands. The sand clouds and the damped air influence the air quality of Bahrain. The seasonal climatic variation also influences human activities. According to the Bahrain event calendar, most outdoor activities were organized during the winter season. During extreme summer climatic conditions, the government also imposes a two-month-long ban on outdoor work between noon and 4 p.m. Hence, in Bahrain, climatic factors are much more influential on the environment and behavior patterns.

\section{Variables and methods}

The current study investigates the association of meteorological indicators and pollution indicators such as air temperature, relative humidity, solar radiation, wind velocity, and PM2.5 over the COVID-19 pandemic in Bahrain from 05 April 2020 to 10 January 2021. The total COVID-19 cases, total deaths, and total active cases have been sourced from the John 
Hopkins coronavirus database. In addition, the dataset for temperature, humidity, shortwave radiation, wind speed, and $\mathrm{PM}_{2.5}$ has been obtained from The Supreme Council for Environment, Kingdom of Bahrain database.

\section{Specification of the model}

To investigate the COVID-19 pandemic in Bahrain, we rely on Kendall and Spearman rank correlation coefficients and wavelet transform coherence. Kendall and Spearman rank correlation test was used to measure the degree of linear association between variables and has been extensively used in the existing literature as it originates from covariance methodology. Pearson correlation test also provides information about the extent of links among variables under consideration and calculates the nature of such association with empirical estimates ranging between -1 or +1 . The mathematical form of the Pearson correlation coefficient can be estimated through equation (1).

$r_{s}=\frac{\sum_{i}\left(x_{i}-\bar{x}\right)\left(y_{i}-\bar{y}\right)}{\sqrt{\left(x_{i}-\bar{x}\right)^{2} \sqrt{\left(y_{i}-\bar{y}\right)^{2}}}}$

By relying on monotonic function, the rank correlation coefficient $\left(r_{s}\right)$ controls the correlation between variables to assess the monotonic association. If no data reputation can be observed, then -1 or +1 occurs when every variable in each other's perfect monotonic function. Equation 2 provides the empirical estimation of the coefficient $\left(r_{s}\right)$, where data is explained by $n$ and difference in the rank of the $i^{\text {th }}$ element is narrated by $d_{i}$. The sign of empirical findings indicates the association between the independent and dependent variables. The Spearman correlation coefficient values are positive if the dependent variable's value increases with independent variables or vice versa.

$r_{s}=1-\frac{6 \sum_{i} d_{i}^{2}}{n\left(n^{2}-1\right)}$

We also use the Kendall rank correlation coefficient to investigate the degree of impact based on the observations' pairs. Kendall rank correlation test is used to analyze the parallels in ordering data when quantiles rank it. While other correlation tests use data observations as a base of correlation, Kendall correlation tests account for such association through discordance among pairs. Equation (3) provides a mathematical form of the Kendall rank correlation test.

$\mathcal{T}=\frac{n_{c}-n_{d}}{\frac{1}{2} n(n-1)}$
In equation (3), total observations, no of discordant, and number of concordant are explained by $n, n_{d}$, and $n_{c}$. The coefficient estimates are generally smaller than Spearman correlation tests and are most accurate for small dataset.

We further use wavelet transform coherence as a main analytical structure, which provides graphical correlation to examine the association between the current research project's data. Arrows are used to explore the correlation's impact and direction from one variable to another in wavelet coherence. The strength of effects is illustrated by color in the graphical representations as movement from yellow to blue indicates weak association or vice versa. The cone of influence separates the significant region from the rest, with a thick black lining drawn from top to bottom on both sides.

\section{Quantile-on-quantile regression}

For the main empirical analysis, we rely on quantile-onquantile regression. QQ approach is standard quantile regression's more general form, which allows examining the effect on quantile variables on other conditional quantile variables and statistically is the combination of non-parametric and quantile regression. The current study investigates the asymmetric association between meteorological indicators and cases related to the second wave of COVID-19 outbreak in Bahrain and will provide a more detailed and reliable overview of the statistical association between the two variables.

Shahbaz et al. (2018) illustrated that the QQR approach provides more robust findings than traditional quantile regression analysis and uses the following three steps during the analytical stage. First, a local linear regression is used to evaluate the effect of a specific quantile of specific meteorological variables and vice versa by assigning further weights to values in the adjacent quantiles to overcome dimensionality. Second, the effect of a predictor variable is examined through classical quantile regression on various quantiles of the criterion variable. Third, the impact of an indicator is tested through classical linear regression technique at both head and tail quantiles of the data distribution or vice versa. Sharif et al. (2019) suggested that QQR methodology incorporates both the quantile and nonparametric approach's properties and regresses the variables' quantiles included in the empirical analysis and vice versa to capture spatial and asymmetric properties over time. The current study uses the following equation, based on nonparametric quantile regression, for empirical analysis:

$C 19_{t}=\beta^{\varnothing}\left(X_{t}\right)+\varepsilon_{t}^{\varnothing}$

where $C 19_{t}$ is COVID-19 in Bahrain at given period $t . X_{t}$ is the meteorological indicators in Bahrain at given period $t . \varnothing$ is the $\varnothing$ th quantile of the conditional distribution growth of $\mathrm{C} 19$. 
$\varepsilon_{t}^{\varnothing}$ is the quantile residual term, whose conditional $\varnothing$ th quantile is supposed to have zero value.

The application of quantile regression allows analyzing the impact of different meteorological variables and COVID-19 cases at different quantile in Bahrain. Furthermore, quantile regression is a flexible analytical approach. It can evaluate the functional dependence between COVID-19 cases and different variables. The key advantage is the specification of its flexibility, as the functional association between meteorological variables and COVID-19 cases has not been previously assumed.

\section{Results and discussion}

Table 1 provides the empirical estimates of Kendall and Spearman correlation tests. For the Kendall correlation test, humidity, wind speed, and solar radiation are significant meteorological indicators regarding daily new COVID-19 cases in the kingdom of Bahrain. Temperature and $\mathrm{PM}_{2.5}$ report negative yet statistically insignificant association with the daily new cases. The Spearman rank correlation test estimates that humidity and solar radiation significantly affect confirmed newly infected cases. Temperature and wind speed have a positive yet insignificant association, while $\mathrm{PM}_{2.5}$ reports a negative association.

\section{Discussion quantile-on-quantile regression (QQR)}

The current study used the QQR approach to examine the association between COVID-19 daily new cases and meteorological indicators in the Kingdom of Bahrain. Figure 3 represents the QQR slope coefficients through three-dimensional graphs, where the first column can capture the effect of $\tau_{\text {th }}$ quantile of the variable on $\theta_{\text {th }}$ equidistant quantile of COVID-19, as represented by $\beta_{1}(\theta, \tau)$. The graphical representation of Fig. 3 clearly illustrates that the association between meteorological variables and the COVID-19 is symmetrical, but the shape of these quantiles varies substantially across different quantiles.

Figure 3(a) reveals the association between temperature and COVID-19 cases in the Kingdom of Bahrain. According to the graphical illustration, there is generally a moderate association between the two indicators, especially at the middle and high quantiles. Past literature of Vandini et al. (2013) and Tan et al. (2005) supported such findings with the earlier viral outbreaks of SARS and MARS as they belong to exact coronavirus origins. A recent study by Bilal et al. (2021b) also concluded that meteorological indicators play a key part in spreading infectious diseases, especially during the winter. Next, Fig. 3(b) illustrates the association between humidity and daily COVID-19 newly infected cases. Humidity, an integral climate indicator, has been well documented in treating respiratory diseases, especially during the coronaviruses' seasonal spread (Sajadi et al. 2020). Wang et al. (2020) investigated the outbreak of COVID-19 in Wuhan (China) to report that the outbreak of COVID-19 was positively correlated with climate indicators. The research article further articulated that summer arrival may be influential in reducing infection rates from COVID-19 in southern China. Finally, the research team suggested that the association between humidity and air quality needs to be further examined to spread infectious diseases (Chen et al. 2020). Ma et al. (2020) investigated humidity in the COVID-19 outbreak to explain that temperature and humidity play a significant role in spreading the pandemic.

Figure 3(c) examined the association between shortwave radiation and COVID19 cases, revealing a strong association at middle and high quantiles. Past studies of Tan et al. (2005) and Vandini et al. (2013) have reported that meteorological indicators are key determinants of infectious diseases. Several researchers such as Oliveiros et al. 2020, Ma et al. 2020, and Luo et al. 2020 also explored similar association to report that although meteorological indicators increase the risk of getting infected from viral outbreaks such as SARS, MERS, and the COVID-19 but solar radiation and temperature need further research to determine their exact impact over the
Table 1 Kendall and Spearman correlation tests

\begin{tabular}{|c|c|c|c|c|}
\hline $\begin{array}{l}\text { Coefficient } \\
\text { Variables }\end{array}$ & $\begin{array}{l}\text { Kendall rank } \\
\text { correlation test } \\
\text { Daily new } \\
\text { cases }\end{array}$ & Association & $\begin{array}{l}\text { Spearman rank } \\
\text { correlation test } \\
\text { Daily new cases }\end{array}$ & Association \\
\hline $\begin{array}{c}\text { Temperature } \\
\left({ }^{\circ} \mathrm{C}\right)\end{array}$ & -0.011 & Negative yet insignificant & 0.002 & Positive yet insignificant \\
\hline $\begin{array}{l}\text { Relative } \\
\text { humidity }\end{array}$ & $-0.079 * * *$ & Significant & $-0.131 * * *$ & Significant \\
\hline Wind speed & $0.381 * * *$ & Significant & 0.574 & Positive yet insignificant \\
\hline $\begin{array}{l}\text { Solar } \\
\quad \text { radiation }\end{array}$ & $0.102 * * *$ & Significant & $0.155 * * *$ & Significant \\
\hline $\mathrm{PM}_{2.5}$ & -0.031 & Negative yet insignificant & $'-0.047$ & Negative association \\
\hline
\end{tabular}



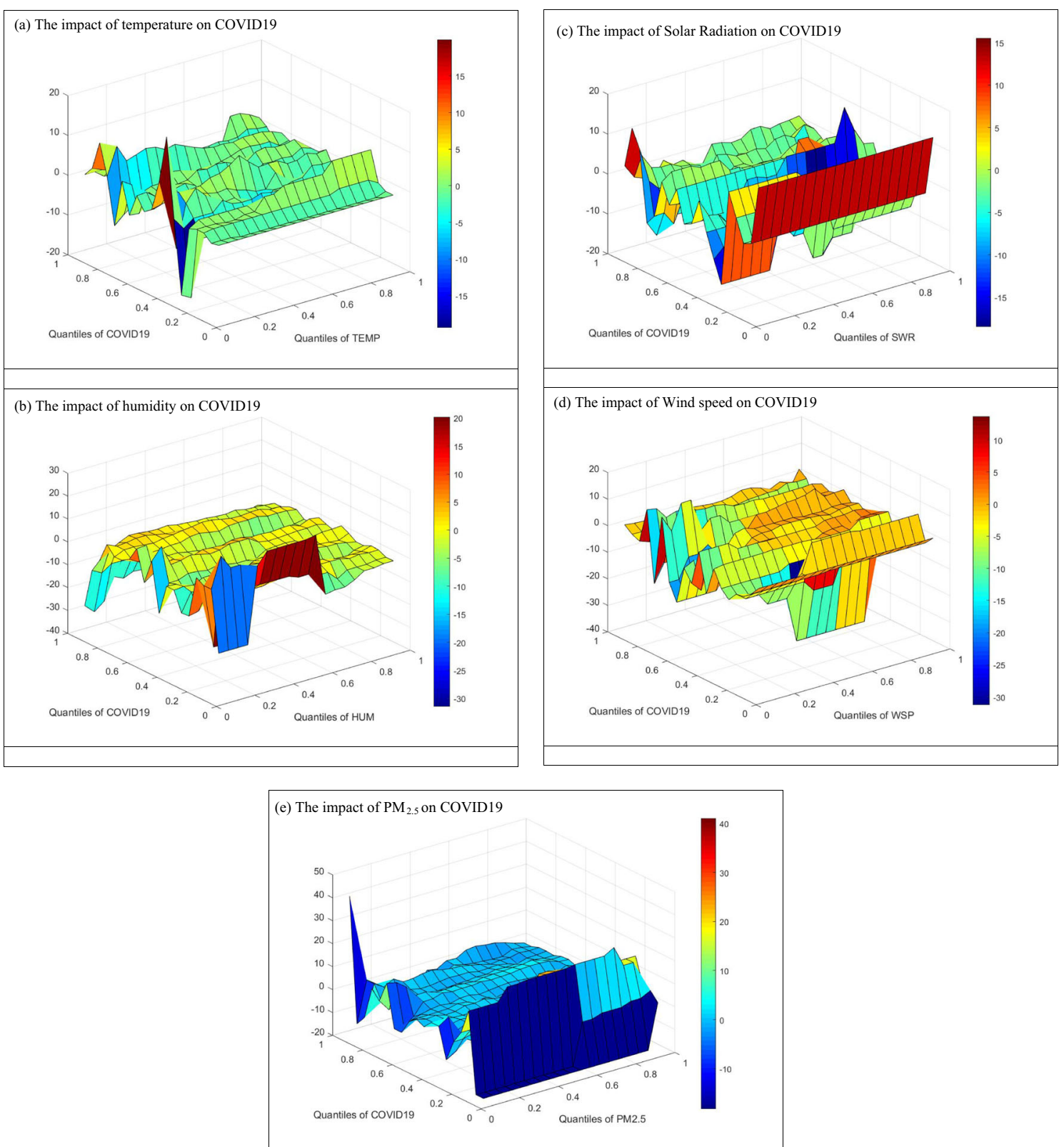

Fig. 3 (a) The impact of temperature on COVID-19. (b) The impact of humidity on COVID-19. (c) The impact of solar radiation on COVID-19. (d) The impact of wind speed on COVID-19. (e) The impact of $\mathrm{PM}_{2.5}$ on COVID-19

coronaviruses (Bilal et al. 2020a, b). Figure 3(d) illustrates the relationship between wind speed and daily confirmed newly infected cases. According to the findings, it shows moderate to strong association at high quantiles. Another perspective of economic literature has investigated a combination of environmental and meteorological indicators and their association with COVID-19. It was argued that indicators such as solar radiation, $\mathrm{PM}_{2.5}$, and surface air pollution contribute significantly to the COVID-19 (Kirby 2020). Another study investigated the lethality of the COVID-19 and environmental indicators to suggest that lower environmental quality in the urban areas is the main reason for the high infectious trend in urban areas (Ran et al. 2020) to higher deaths and reported cases in the metropolitan vicinities. Shi et al. (2020) empirically analyzed the association between climate indicators such as wind and solar radiation in the Chinese provinces to determine that solar radiation and wind are important indicators in the outbreak of the COVID-19 in Chinese cities.

Lastly, Fig. 3(e) provides a graphical representation of the association between $\mathrm{PM}_{2.5}$ and COVID-19 daily new cases to report a strong negative association between the variables included in the study. Several studies explored the impact of $\mathrm{PM}_{2.5}$ on infectious diseases and how it impacts the COVID-19 outbreak. Wu et al. (2020) examined the association between environmental pollution $\left(\mathrm{PM}_{2.5}\right)$ and COVID-19 to indicate that the mortality rate from COVID-19 outbreak increases by $15 \%$ with a one 
Fig. 4 (a) The impact of air temperature on COVID-19. (b)

The impact of humidity on

COVID-19. (c) The impact of shortwave radiation on COVID-

19. (d) The impact of wind speed on COVID-19. (e) The impact of

PM2.5 on COVID-19
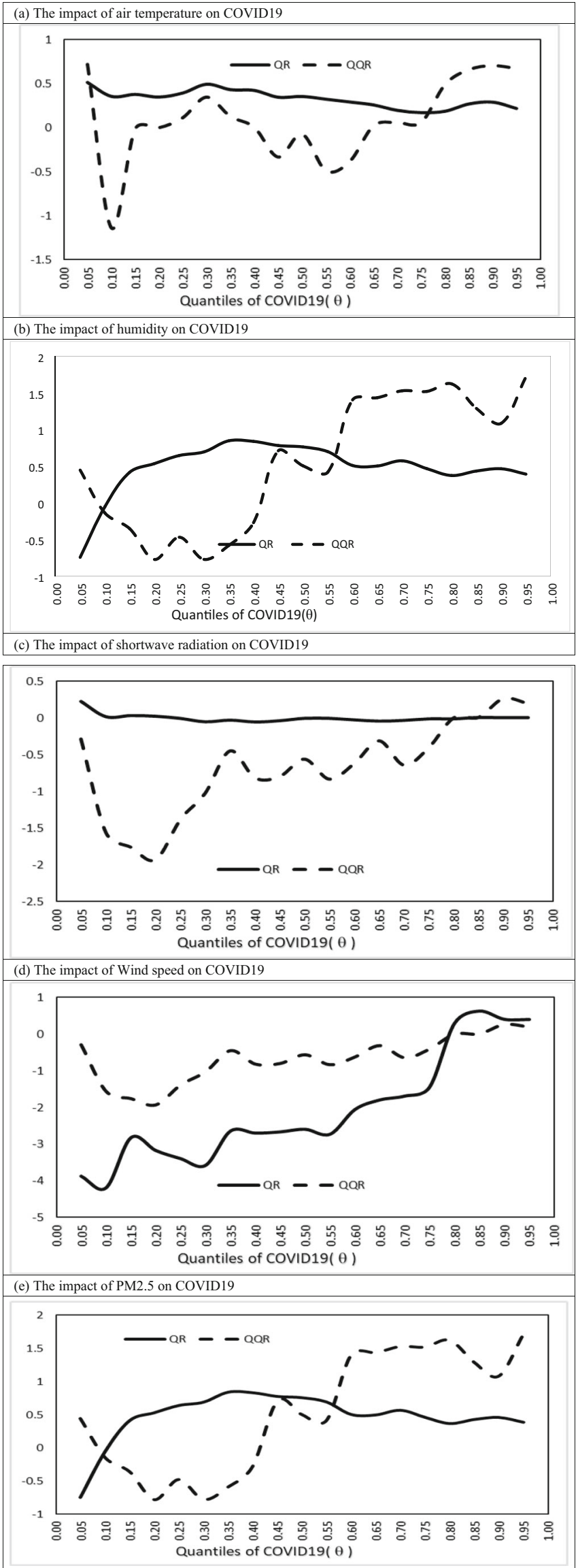
$\mathrm{ug} / \mathrm{m}^{3}$ increase in particulate emissions. Similar findings were reported by Piazzalunga-Expert (2020), Wang et al. (2020), and Fann and Risley (2013) for Italy, China, and the USA. A portion of studies investigates the demographic changes in urban areas. Such a shift in population density can contribute to higher environmental pollution and contribution to chronic illnesses. Pandey et al. (2005) were one of the first to investigate the emission of environmental pollution in New Delhi, India, to conclude that residential areas near industrial cites reported higher environmental pollution and susceptible infectious diseases mainly due to vulnerable immune system, especially in children and elderly. The researchers finally concluded that environmental pollution levels in New Delhi were 22 times worse than in other residential complexes (Bilal et al. 2020a).

\section{Testing the validity of the QQ method}

The current study used the QQR approach (Bashir et al. 2021a, b) to examine the association of $\tau_{\text {th }}$ indicator quantile on $\theta_{\text {th }}$ quantile of COVID-19 and vice versa at different values of the respective quantiles. Hence, providing us with more comprehensive analytics due to its ability to capture asymmetric effects across equidistant quantiles of $\tau$ and $\theta$. However, economists argue that the average slope parameters of QQR must not deviate too much from the traditional QR approach. Keeping in mind the decomposition attributes of QR methodology, the QR approach can be useful in recovering the estimates from the standard quantile regression. To be precise, the quantile regression parameter indexed only by $\theta$ can be generated by averaging the QQ parameter along $\tau$ (Bashir et al. 2015, 2020a; Shahbaz et al. 2021).

The graphical illustration of Fig. 4 indicates that the mean estimates of the QQR approach are approximately parallel to the $\mathrm{QR}$ approach and generally move in the same direction. In some cases, such as 4(b) for humidity and 4 (d) wind speed, the trend estimates for the QQR approach do not significantly vary from the QR. Still, the illustration of estimates is somewhat dissimilar. The graphical evidence postulates that the estimates from the quantile regression model can be recovered from the summary of detailed information available in QQ estimates. These findings authenticate our prior results of the QQR approach.

\section{Activity measures and COVID-19 pandemic}

Figure $5 \mathrm{a}$ represents the results of the activities measured in percentage (\%) during the pandemic, and Fig. 5b shows the newly infected COVID-19 cases. Google Mobility Tracking collected this data for Bahrain, and it is available online for worldwide countries (Data 2021). Figure 5a represents the percentage (\%) of people who stayed at home, went to retail and recreation establishments, went to the grocery store and pharmacy, went out into the open spaces and parks, went to transit stations, and went to their workplaces between 05 April 2020 and 10 January 2021. According to the above figures, when the percentage (\%) of people who stay at home increases, the number of newly infected cases is reduced. At the same time, as the percentage (\%) of staying at home decreases, the infected cases also increase. When people participate in outdoor activities in parks, transit stations, workplaces, retail and recreation centers, grocery stores, and pharmacies, the number of newly infected and fatal cases noticeably increases.

In contrast, such cases decreased when participation in these activities dropped. Table 2 represents the statistical association between the implemented measures and the COVID-19 new cases. The COVID-19 newly infected cases are positively correlated with people who stay at home, in parks, or use transit stations. On the other hand, compared with the newly reported cases of infection, people in grocery stores, pharmacies, retail stores, recreation centers, and workplaces have a slightly negative correlation. Therefore, it can be concluded that restrictions that aim to reduce the number of people in outdoor activities and encourage them to stay at home tend to reduce the COVID-19 cases. On the contrary, loosening the restrictions on these activities caused the COVID-19 outbreak and cases to increase.

\section{Conclusion}

This study investigates the association between daily reported new COVID-19 cases and environmental and meteorological indicators in Bahrain's hot arid climate region. For empirical analysis, the current study mainly relies on quantile-on-

Table 2 COVID-19 newly infected cases and activities measures

\begin{tabular}{llllllll}
\hline Activities measures & Spearman $(r s)$ & $P$-value & Pearson's $(r)$ & $P$-value & Kendall & $p$-value & Correlation \\
\hline Staying at home & 0.12471 & 0.03947 & 0.01686 & 0.78153 & 0.10391 & 0.01122 & $\begin{array}{l}\text { Positive correlation } \\
\text { Grocery and pharmacy }\end{array}$ \\
Outdoor and Parks & -0.07207 & 0.23526 & -0.08514 & 0.16068 & -0.06352 & 0.1207 & Negative correlation \\
Retail and recreational & -0.01422 & 0.81505 & 0.16942 & 0.00501 & 0.0146 & 0.72067 & Positive correlation \\
Transit stations & 0.08645 & 0.03824 & 0.07573 & 0.21228 & -0.10702 & 0.00878 & Negative correlation \\
Work Places & 0.05392 & 0.374429 & 0.13317 & 0.0278 & 0.08179 & 0.04493 & Positive correlation \\
& & 0.8879 & 0.1434 & -0.00948 & 0.81688 & Negative correlation \\
\hline
\end{tabular}


Fig. 5 COVID-19 activity measures and COVID-19 pandemic in Bahrain

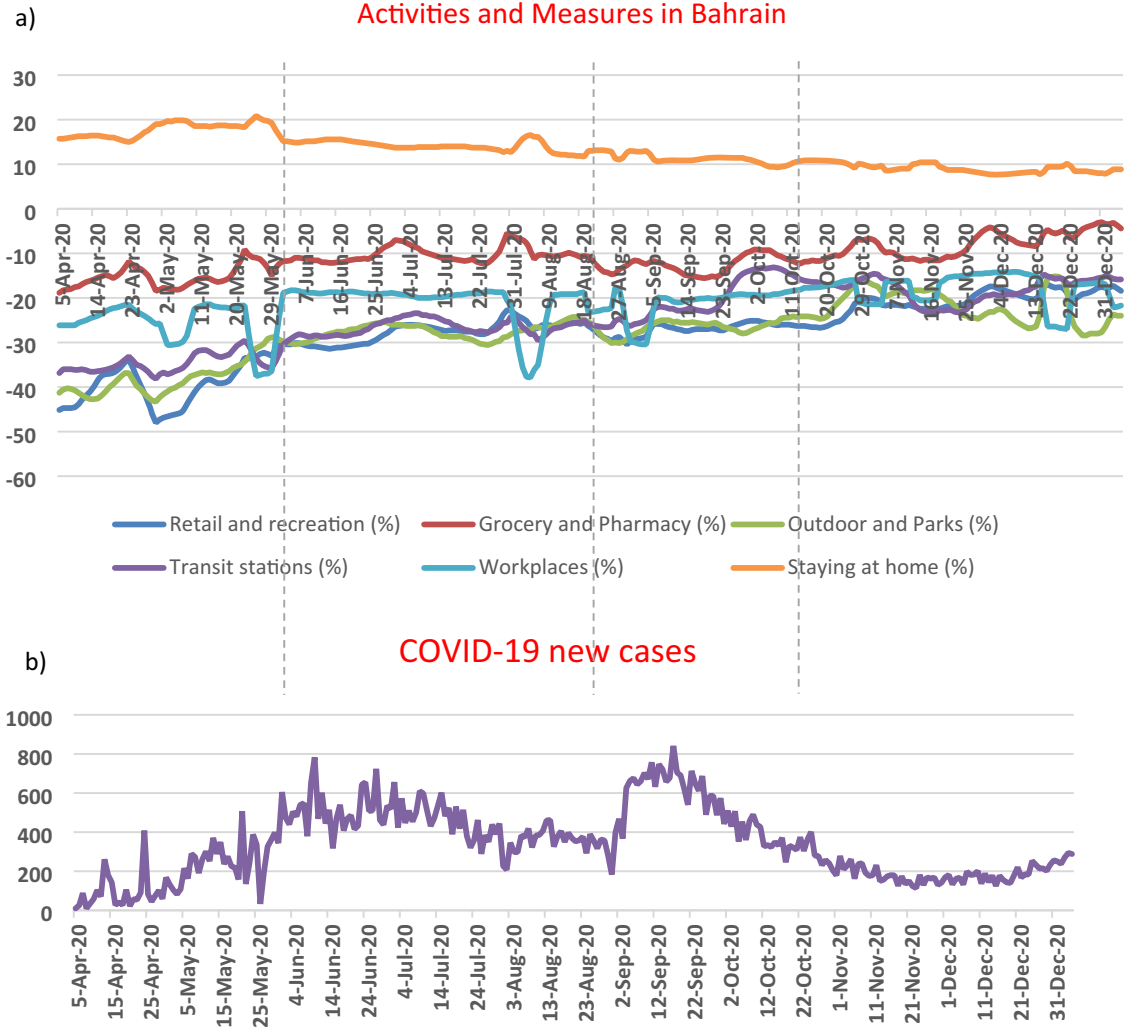

quantile regression analysis to confirm how each quantile of environmental and meteorological indicator affects each quantile of COVID-19 cases. This empirical approach allows us to provide a complete description of the overall dependence of the environmental and meteorological indicators and COVID-19 pandemic and provides reliability about the interaction of the variables included by the current study.

The findings of Kendall and Spearman rank correlation tests indicate that wind speed, humidity, and solar radiation are associated with COVID-19 cases and mildly associated with COVID-19 newly infected cases. The empirical approach of quantile-on-quantile regression reveals a moderate association between the two indicators, especially at the middle and high quantiles. The association between humidity and daily COVID-19 newly infected cases is significant at lower and middle quantiles. Next, the analysis of shortwave radiation and COVID19 cases has reported a strong association at middle and high quantiles. Meanwhile, empirical analysis between wind speed and daily confirms moderate to strong association at high quantiles. Lastly, the association between $\mathrm{PM}_{2.5}$ and COVID-19 daily new cases indicates a strong negative at high quantiles

The Gulf countries have recently seen an increase in COVID-19 cases, and these countries are taking extreme measures to stop the spread of the virus. However, meteorological factors could increase the risk for some respiratory diseases, and people might be infected by pathogens much more easily. The reason may be the increased-out door temperatures, high solar radiation intensity, high humidity, and warm air, which prompted people to indoor activity and increased the risk of transmission spread by airborne and close contact. Therefore, this research's findings may help authorities restrict activities during seasonal climate variation in the region. Furthermore, the meteorological data can indicate to determine the certain type of activities while keeping economic activities unaffected.

We highlight some of the limitations of a current research project. First, we have investigated Bahrain, a small island nation with limited financial resources, to overcome the COVID-19 pandemic. Hence, further research is needed to incorporate countries in the hot and arid region to examine the association between meteorological factors and respiratory diseases over a larger sample size, which will provide significant suggestions to deal with future pandemics. Second, though quantile on quantile regression, it must be interpreted cautiously. Third, more studies are required to provide triangulate analysis between respiratory disease cases, meteorological factors, and activity patterns.

Availability of data and materials Data and relevant materials will be available from the corresponding author through email.

Author contribution Adeb Qaid: writing-original draft. Dilshan Remaz Ossen: project supervision. Muhammad Farhan Bashir: methodology, writing the original draft, data analysis, revision, and conceptualization. Khurram Shahzad: supervision, data analysis, revising, reviewing, and editing. 
Funding Not applicable.

\section{Declarations}

Ethics approval Not applicable.

Consent to participate Not applicable.

Consent for publication Not applicable.

Competing interests The authors declare competing interests.

\section{References}

Altamimi A, Ahmed AE (2020) Climate factors and incidence of Middle East respiratory syndrome coronavirus. Journal of Infection and Public Health 13(5):704-708. https://doi.org/10.1016/j.jiph.2019. 11.011

Arslan H, Bilal, Bashir, MF (2021) Contemporary research on spillover effects of COVID-19 in stock markets. A systematic and bibliometric review. Sciform Proceedings, pp 1-14. https://doi.org/ 10.3390/ECERPH-3-09103

Bashir MF, Shahzad U, Latif S, Bashir M (2015) The Nexus between economic indicators and economic growth in Brazil. Nexus 13(1)

Bashir MF, MA B, Shahbaz M, Jiao Z (2020a) The nexus between environmental tax and carbon emissions with the roles of environmental technology and financial development. PLoS ONE 15(11): e0242412. https://doi.org/10.1371/journal.pone.0242412

Bashir MF, Ma B, Bilal KB, Bashir MA, Tan D, Bashir M (2020b) Correlation between climate indicators and COVID-19 pandemic in New York, USA. Sci Total Environ 728:138835. https://doi.org/ 10.1016/j.scitotenv.2020.138835

Bashir MF, Ma BJ, Bilal K, Bashir MAB, Farooq TH, Iqbal N, Bashir M (2020c) Correlation between environmental pollution indicators and COVID-19 pandemic: a brief study in Californian context. Environ Res 187:109652. https://doi.org/10.1016/j.envres.2020.109652

Bashir MF, Ma B, Shahzad L (2020d) A brief review of socio-economic and environmental impact of covid-19. Air Qual Atmos Health 13(12):1403-1409. https://doi.org/10.1007/s11869-020-00894-8

Bashir MF, Ma B, Qin Y et al (2021a) Evaluation of one belt one road publications: a bibliometric and literature review analysis. Environ Sci Pollut Res. https://doi.org/10.1007/s11356-021-14621-y

Bashir MF, Ma B, Bashir MA et al (2021b) Scientific data-driven evaluation of academic publications on environmental Kuznets curve. Environ Sci Pollut Res 28:16982-16999. https://doi.org/10.1007/ s11356-021-13110-6

Biktasheva IV (2020) Role of a habitat's air humidity in covid-19 mortality. Sci Total Environ 736:138763. https://doi.org/10.1016/j. scitotenv.2020.138763

Bilal BMF, Benghoul M, Numan U, Shakoor A, Komal B, Bashir MA, Bashir M, Tan D (2020a) Environmental pollution and COVID-19 outbreak: insights from Germany. Air Qual Atmos Health 13(11): 1385-1394. https://doi.org/10.1007/s11869-020-00893-9

Bilal, Latif F, Bashir MF, Komal B, Tan D (2020b) Role of electronic media in mitigating the psychological impacts of novel coronavirus (COVID-19). Psychiatry Res 289:113041. https://doi.org/10.1016/j. psychres.2020.113041

Bilal, Bashir MF, Shahzad K et al (2021a) Environmental quality, climate indicators, and COVID-19 pandemic: insights from top 10 most affected states of the USA. Environ Sci Pollut Res Int:1-10. https://doi.org/10.1007/s11356-021-12646-x
Bilal, Bashir MF, Komal B, Benghoul M, Bashir MA, Tan D (2021b) Nexus between the COVID-19 dynamics and environmental pollution indicators in South America. Risk management and healthcare policy 14:67-74

Bilal, Bashir, MF, Shahzad A, Komal B, Bashir MA, Tan D (2021c) Nexus between temperature and COVID-19 pandemic: a meta-analysis. Sci Forum Proceedings, pp 1-5. https://doi.org/10.3390/ ECERPH-3-09098

Chen B, Liang H, Yuan X, Hu Y, Xu M, Zhao Y (2020) Roles of meteorological conditions in COVID-19 transmission on a worldwide scale. medRxiv. https://doi.org/10.1101/2020.03.16.20037168

Cucinotta D, Vanelli M (2020) WHO declares COVID-19 a pandemic. Acta Bio Medica Atenei Parmensis 91(1):157-160. https://doi.org/ 10.23750/abm.v91i1.9397

Dalziel BD, Kissler S, Gog JR, Viboud C, Bjørnstad ON, Metcalf CJE, Grenfell BT (2018) Urbanization and humidity shape the intensity of influenza epidemics in U.S. cities. Science 362:75-79. https://doi. org/10.1126/science.aat6030

Data W (2021) Google Mobility Trends: how has the pandemic changed the movement of people around the world? https:/ourworldindata. org/covid-mobility-trends\#grocery-and-pharmacy-stores. Accessed 15 Jan 2021

Diaz RS, Vergara TRC (2020) The COVID-19 second wave: a perspective to be explored. BrazJ infect Dis : an official publication of the Brazilian Society of Infectious Diseases 25:101537. https://doi.org/ 10.1016/j.bjid.2020.101537

Fann N, Risley D (2013) The public health context for PM 2.5 and ozone air quality trends. Air Qual Atmos Health 6(1):1-11. https://doi.org/ 10.1007/s11869-10-0125-0

Fofana NK, Latif F, Sarfraz S, Bashir MF, Komal B (2020) Fear and agony of the pandemic leading to stress and mental illness: an emerging crisis in the novel coronavirus (COVID-19) outbreak. Psychiatry Res 291:113230. https://doi.org/10.1016/j.psychres. 2020.113230

Health Mo (2021) Publication https://www.moh.gov.bh/COVID19/ Publications. Accessed 13/02/2021

HOPKINS J (2021) New cases of COVID-19 in world countries. https:// coronavirus.jhu.edu/data/new-cases. Accessed 13/02/2021

Kirby T (2020) South America prepares for the impact of COVID-19. The Lancet Respiratory Medicine. https://doi.org/10.1016/S22132600(20)30218-6

Li Q, Guan X, Wu P, Wang X, Zhou L, Tong Y, Ren R, Leung KSM, Lau EHY, Wong JY, Xing X, Xiang N, Wu Y, Li C, Chen Q, Li D, Liu T, Zhao J, Liu M, Tu W, Chen C, Jin L, Yang R, Wang Q, Zhou S, Wang R, Liu H, Luo Y, Liu Y, Shao G, Li H, Tao Z, Yang Y, Deng Z, Liu B, Ma Z, Zhang Y, Shi G, Lam TTY, Wu JT, Gao GF, Cowling BJ, Yang B, Leung GM, Feng Z (2020) Early transmission dynamics in Wuhan, China, of novel coronavirus-infected pneumonia. N Engl J Med 382(13):1199-1207. https://doi.org/10.1056/ NEJMoa2001316

Luo W, Majumder M, Liu D, Poirier C, Mandl K, Lipsitch M, Santillana M (2020) The role of absolute humidity on transmission rates of the COVID-19 outbreak. medRxiv. https://doi.org/10.1101/2020.02.12. 20022467

Ma Y, Zhao Y, Liu J, He X, Wang B et al (2020) Effects of temperature variation and humidity on the death of COVID-19 in Wuhan, China. Science of The Total Environment 724:138226. https://doi.org/10. 1016/j.scitotenv.2020.138226

Oliveiros B, Caramelo L, Ferreira NC, Caramelo F (2020) Role of temperature and humidity in the modulation of the doubling time of COVID-19 cases. medRxiv. https://doi.org/10.1101/2020.03.05. 20031872

Pandey JS, Kumar R, Devotta S (2005) Health risks of NO2, SPM and SO2 in Delhi (India). Atmos Environ 39(36):6868-6874

Pani SK, Lin N-H, RavindraBabu S (2020) Association of COVID-19 pandemic with meteorological parameters over Singapore. Sci Total 
Environ 740:140112. https://doi.org/10.1016/j.scitotenv.2020. 140112

Paraskevis D, Kostaki EG, Alygizakis N, Thomaidis NS, Cartalis C, Tsiodras S, Dimopoulos MA (2021) A review of the impact of weather and climate variables to COVID-19: In the absence of public health measures high temperatures cannot probably mitigate outbreaks. Sci Total Environ 768:144578. https://doi.org/10.1016/j. scitotenv.2020.144578

Piazzalunga-Expert A (2020) Evaluation of the potential relationship between particulate matter (PM) pollution and COVID-19 infection spread in Italy. Societa Italiana Di Medicina Ambientale 1-6

Ran L, Wang W, Ai M, Kong Y, Chen J, Kuang L (2020) Psychological resilience, depression, anxiety, and somatization symptoms in response to COVID-19: a study of the general population in China at the peak of its epidemic. Soc Sci Med 262:113261

Rosario DKA, Mutz YS, Bernardes PC, Conte-Junior CA (2020) Relationship between COVID-19 and weather: case study in a tropical country. Int J Hyg Environ Health 229:113587. https://doi.org/ 10.1016/j.ijheh.2020.113587

Şahin M (2020) Impact of weather on COVID-19 pandemic in Turkey. Sci Total Environ 728:138810. https://doi.org/10.1016/j.scitotenv. 2020.138810

Sajadi MM, Habibzadeh P, Vintzileos A, Shokouhi S, Miralles-Wilhelm F, Amoroso A (2020) Temperature, humidity, and latitude analysis to estimate potential spread and seasonality of coronavirus disease 2019 (COVID-19). JAMA Netw Open 3(6):e2011834-e2011834

Shahbaz M, Zakaria M, Shahzad SJH, Mahalik MK (2018) The energy consumption and economic growth nexus in top ten energyconsuming countries: fresh evidence from using the quantile-onquantile approach. Energy Econ 71:282-301

Shahbaz M, Bashir MF, Bashir MA et al (2021) A bibliometric analysis and systematic literature review of tourism-environmental degradation nexus. Environ Sci Pollut Res. https://doi.org/10.1007/s11356$021-14798-2$

Shakil MH, Munim ZH, Tasnia M., Sarowar S (2020) COVID-19 and the environment: a critical review and research agenda. Science of The Total Environment 745:141022. https://doi.org/10.1016/j.scitotenv. 2020.141022

Sharif A, Afshan S, Qureshi MA (2019) Idolization and ramification between globalization and ecological footprints: evidence from quantile-on-quantile approach. Environ Sci Pollut Res 26(11): $11191-11211$

Shi P, Dong Y, Yan H, Li X, Zhao C, Liu W, He M, Tang S, Xi S (2020) The impact of temperature and absolute humidity on the coronavirus disease 2019 (COVID-19) outbreak-evidence from China. medRxiv. https://doi.org/10.1101/2020.03.22.20038919

Tan J, Mu L, Huang J, Yu S, Chen B, Yin J (2005) An initial investigation of the association between the SARS outbreak and weather: with the view of the environmental temperature and its variation. J Epidemiol Community Health 59(3):186-192 https://doi.org/10.1136/jech. 2004.020180

Tayech A, Mejri MA, Makhlouf I, Mathlouthi A, Behm DG, Chaouachi A (2020) Second wave of COVID-19 global pandemic and athletes' confinement: recommendations to better manage and optimize the modified lifestyle. Int J Environ Res Public Health 17(22). https:// doi.org/10.3390/ijerph17228385

Tosepu R, Gunawan J, Effendy DS, Ahmad LOAI, Lestari H, Bahar H, Asfian P (2020) Correlation between weather and covid-19 pandemic in Jakarta, Indonesia. http://www.sciencedirect.com/science/ article/pii/S0048969720319495

Vandini S, Corvaglia L, Alessandroni R, Aquilano G, Marsico C, Spinelli M, Lanari M, Faldella G (2013) Respiratory syncytial virus infection in infants and correlation with meteorological factors and air pollutants. Ital J Pediatr 39(1):1. https://doi.org/10.1186/1824-7288-39-1

Wang P, Chen K, Zhu S, Wang P, Zhang H (2020) Severe air pollution events not avoided by reduced anthropogenic activities during COVID-19 outbreak. Resour Conserv Recycl 158:104814. https:// doi.org/10.1016/j.resconrec.2020.104814

Wu X, Nethery RC, Sabath BM, Braun D, Dominici F (2020) Exposure to air pollution and COVID-19 mortality in the United States. States: strengths and limitations of an ecological regression analysis. Science advances 6(45):eabd4049. https://doi.org/10.1101/2020. 04.05.20054502

Yao Y, Pan J, Liu Z, Meng X, Wang W, Kan H, Wang W (2020) No association of COVID-19 transmission with temperature or UV radiation in Chinese cities. Eur Respir J 55(5):2000517. https://doi. org/10.1183/13993003.00517-2020

Zhu N, Zhang D, Wang W, Li X, Yang B, Song J, Zhao X, Huang B, Shi W, Lu R, Niu P, Zhan F, Ma X, Wang D, Xu W, Wu G, Gao GF, Tan W (2020) A novel coronavirus from patients with pneumonia in China, 2019. N Engl J Med 382(8):727-733. https://doi.org/10. 1056/NEJMoa2001017

Publisher's note Springer Nature remains neutral with regard to jurisdictional claims in published maps and institutional affiliations. 